\title{
UN PROYECTO PARA ABRIR UN NUEVO CAMINO DESDE LA COSTA CARIBEÑA A LA CIUDAD DE LA NuEVA GUATEMALA EN EL SIGLO XVIII
}

\author{
An Attempt to Open a Route from the Caribbean Coast to the New Guatemala City in the 18th Century
}

\author{
Rafal Reichert
}

\section{Introducción}

E n 1792, Antonio Porta y Costa redactó el documento "Relación del reconocimiento que, de orden del Exmo. Señor Presidente, gobernador y Capitán General D. Bernardo Troncoso, practico el ingeniero ordinario D. Antonio Porta en la costa comprendida desde Omoa hasta la Punta de Manabique; y desde la Barra del Río de Motagua, hasta donde se le une el de Chicozapote a 14 leguas de la ciudad de Guatemala", el cual se conserva en el Archivo General de la Nación de México.

Transcribimos este documento con el objetivo de presentar una original información sobre los esfuerzos que hizo el gobernador de la Capitanía General de Guatemala, don Bernardino Troncoso, para promover y mejorar la comunicación entre la Nueva Guatemala de la Asunción, capital del reino guatemalteco desde 1776,y la costa caribeña. El mariscal de campo envió en misión de reconocimiento al ingeniero don Antonio Porta y Costa para que estudiase las posibilidades de abrir un nuevo camino fluvial-terrestre por el río Motagua que comunicara la capital con el puerto de Omoa.
Rafal Reichert, doctor en historia por la Universidad Nacional Autónoma de México. Temas de especialización: historia colonial del Gran Caribe, historia económica, historia militar y arqueología marítima. Investigador en el Centro de Estudios Superiores de México y Centroamérica de la Universidad de Ciencias y Artes de Chiapas. Correo electrónico: rafreich@yahoo.com.
El ingeniero ejecutó su expedición en mayo de 1792. Durante su aventura realizó múltiples observaciones sobre el Motagua y otros ríos que se unían a éste, midió detalladamente profundidades y corrientes y enumeró los obstáculos que pudieran afectar la navegación. Asimismo, durante su viaje estudió las márgenes de dichos ríos, sus poblaciones y los territorios adyacentes. Con precisión describió las comunidades que encontró en su camino y también la utilidad de la tierra para producción agropecuaria.

A partir de sus observaciones puede imaginarse cómo era la vida campesina a finales del siglo XVIII, qué se cultivaba en la región del río Motagua, quién la poblaba y de qué potencial disponía el área para un científico de la época. Antonio Porta y Costa presentó todas las ventajas y desventajas de este posible nuevo camino. El autor del proyecto incluso expuso los tipos de embarcaciones que podrían atender la nueva ruta comercial y calculó los costos de su mantenimiento con tripulaciones. Elaboró las cuentas, en las que apuntaba el costo que implicaría limpiar el río de troncos y palizadas, además de profundizarlo, regularizarlo y adecuar algunos enclaves de sus orillas 
para establecer parajes en ellas. Calculó estos gastos, que corresponderían a la Real Hacienda, en treinta mil doscientos pesos de a ocho reales.

La última parte de su propuesta presenta la atrevida idea de construir un fuerte en la ensenada de Santo Tomas, cerca de la boca del río Motagua, donde se traspasaría la guarnición del castillo de San Fernando de Omoa. El ingeniero argumentó que este movimiento permitiría ahorrar tiempo, mano de obra y dinero en el transporte desde la costa caribeña hasta la Nueva Guatemala.

Para concluir esta breve introducción, cabe señalar que el proyecto nunca se hizo realidad debido a los altos costos de adecuación del río para su uso como ruta fluvial y, además, porque surgió la propuesta de abandonar el castillo de Omoa. Todo ello implicaría problemas logísticos y administrativos, además de que causaría una carga económica fuerte para el real erario, que mediante esta nueva ruta buscaba ahorrar más que incrementar sus egresos.

Aunque el proyecto no se llevó a cabo, vale la pena conocer su contenido, en el que se aprecia el trabajo científico de Antonio Porta y Costa y sus descripciones del paisaje y de la gente. Desde su visión, para concluir, era beneficioso establecer esta nueva ruta de comunicación entre la capital y la costa caribeña, a la cual arribaban los buques con mercancías metropolitanas y europeas. 
Relacion del reconocimiento que, de orden del Exmo. Señor Presidente, gobernador y Capitan General D. Bernardo Troncoso, practico el ingeniero ordinario D. Antonio Porta en la costa comprendida desde Omoa hasta la Punta de Manabique; y desde la Barra del Rio de Motagua, hasta donde se le une el de Chicozapote a 14 leguas de la ciudad de Guatemala ${ }^{1}$

\section{Exmo. Señor ${ }^{2}$}

Luego que obtube la Orden de V.E. librada en 4 de Abril del corriente año de 1792, relativa a establecer la introduccion, y extraccion de efectos por la Barra y Rio Motagua, con la instruccion que V.E. se sirvio a dirigirme á este efecto, su fecha 15 de Febrero ultimo, emprehendi mi viage el dia 1 de Mayo próximo pasado, en una Piragua, un Bote y dos Canoas con su correspondiente Tripulacion, de que me serví hasta el Pueblo de Gualan. De alli adelante hasta la union del rio Chicosapote con Motagua, me serví solo de las dos Canoas, por ser ya velocidad, ó corriente de las aguas mas viva, y para facilitar mas la subida con esta clase de embarcaciones. Este dia dí principio, levantando el Plano que acompaña, desde el Puerto de Omoa hasta la punta de Manabique, y rio de Motagua, observando las proporciones, que uno y otro ofrecen, calidad del terreno de sus inmediaciones, bocas de los ríos, arroyos, y quebradas que entran en él: cantidad de agua que trae, su velocidad, y sondéo, que se expresará en esta Relacion, que divido por partes, para la mayor inteligencia, segun el reconocimiento, y examen que hice para el proyecto á que aspira el Comercio de esta Capital.

El Puerto de Omoa está abrigado de los vientos del 1 y 2 cuadrante, incluyendo algunas del 3, y los restantes molestan á las embarcaciones, que están fondeadas luego de doblada la ultima punta occidental, que abriga este puerto. Su fondo es lama ${ }^{3}$, mas ó menos suelta, y proximo á tierra, es arena blanca. Los buques que fondean en la Caldera, están resguardados de todos vientos, siendo su fondo de la misma lama, y en las orillas de arena blanca: en este sitio experimentan las embarcaciones mucha broma ${ }^{4}$ : Entra en dicho puerto un rio nombrado Omoa.
Siguiendo la costa á el O., se halla el rio Coto, distante del primero una y media Milla, y de este rio á Punta gorda igual distancia, formando esta con la de Chachaguala, una Ensenada, distante, la primera de la segunda tres Millas.

Desde Punta gorda á la boca del rio Motagua, se hallan los ríos Chachaguala, Cuiamel, y Rio tinto, los quales en el Verano cierran las bocas, y solo en Invierno, y en tiempo de crecidas se abren, y se comunican con la Mar.

Desde el rio Motagua á la punta de Manabique, se hallan Motaguilla, y el rio de San Francisco, los que en Verano sierran las bocas, y solo se abren en tiempo de crecidas en el Invierno, en cuyo espacio está la que llaman Ensenada de San Francisco, la qual no tiene el menor abrigo para ninguna clase de embarcaciones.

Desde Omoa hasta la punta de Manabique es tierra rasa, sin que en esta distancia haya ensenada ni punta (á excepción de la Ensenada de Punta gorda) para poder dar fondo, ni abrigarse ninguna especie de buques, pues le ofenden todos los vientos, menos el del S.; ni hay proporcion en todo este espacio de costa, para formar artíficialmente abrigo para ninguna clase de embarcaciones, mayores ni menores.

La punta de Manabique hace abrigo de los vientos N.E. y S.E. desde la qual corre la costa al S., y luego urtando á el circular hasta Santo Tomas, siendo esta costa rasa, y de aqui empieza á levantar la tierra, y sigue la montaña hasta Bodegas Altas; urtando la costa á el N. y N.N.O. hasta dar con el rio del Golfo, la qual sigue á encontrar la punta de Cocoli, que es tierra alta, y está á la costa de Bacalar que sigue la buelta del Norte.

Los vientos que por lo General Reynan en dicha Costa, son desde Enero ó Febrero, hasta Junio ó mediados de Julio, la Brisa siendo en mayor valor en los meses de Abril y Mayo, por que desde Junio, dan principio las turbonadas, y disipan este viento haciendo á media tarde o cayda del Sol, hacer llamada el viento á la tierra, ó quedarse en calma. El intermedio que hay desde Julio hasta Enero, son los vientos terrales, y los mas fuertes por Octubre y Noviembre, haciendo en esta inmediación algunos Nortes, que estos no cargan mayormente desde la Isla La Utila, hasta el Golfo Dulce; asimismo en estos tiempos reynan; pero muy bonancibles, algunas Brisas, y se hace preciso que el que le sirva la aproveche sin perder instante. 
El Rio Motaguilla consiste en una multitud de Canalisos entre Islotes ó Cayos, formando varias Lagunas, y Ensenadas, circundadas de Manglares: las aguas que entran en él, son de los derrames del Rio Motagua, y estan detenidas en el Verano, y solo en las avenidas corren, y abren Boca á la Mar acia al Norte.

El Río de Motagua entra á la Mar por dos Bocas, y ambas tienen Barra, una al Norte que es la principal, y la otra al N.O.: las dos son peligrosas su entrada, porque varian el Canaliso, segun las crecientes ó avenidas del Rio, y tiempos de la Mar; la del N.O. lo es mas que la del Norte, porque, no tiene mas que de 4 a 5 palmos de agua, y el Canaliso muy estrecho. El Canaliso de la Boca del Norte ó principal tiene 60 varas de longitud 15 de latitud y ocho palmos de agua, y la Barra 300 varas de latitud. En todos tiempos del año es peligrosa su entrada, porque en tiempo de Norte y Brisas, aumenta su bravesa, llegando la reventason como á media legua á la Mar, por cuyo motivo, y la incertidumbre del Canaliso, que varia en todos tiempos, hace tan temible á los naturales y Practicos de la Costa la entrada de ella, causa que se han aogado varios, que han intentado entrar en Canoas.

A la una de la tarde entré por la Barra de dicho Rio de Motagua con el viento á la Brisa, no obstante que los tres dias anteriores no reynaba este viento, y á esta hora no era muy fuerte; la Barra estaba muy alterada, de manera que el Bote estuvo á peligro de sosobrar, y la Piragua en los mismos términos, y una de las canoas se vio obligada a entrar por Motaguilla, y la otra fue arrojada á la Costa, perdiendo todos los viveres, y equipaje de los Marineros; pero se salvaron estos y aquella.

\section{RIO DE MOTAGUA}

Desde la boca de este rio á donde se le une el Río nuevo hay 10 leguas, su anchura hasta este punto, es de 120 á 80 varas. La corriente ó velocidad de las aguas, es de media milla por ora, su profundidad de 32 á 8 palmos; se hallan muchos islotes ó callos, y 7 bajos de 6 á 5 palmos de agua, el fondo de estos, como el del Rio, y playas, es de Arena fina, tiene muchos tornos, bueltas y rebueltas como lo demuestra el Plano. ${ }^{5}$ A 6 leguas de la boca se hallan unos ranchos abitados por seis Negros libres
Ingleses, avecindados en Omoa, que la mayor parte del año se ejercitan sarzeando ${ }^{6}$, la que conducen á aquella Plaza. Las orillas del Rio hasta á qui, su terreno es baxo, y anegadizo; pero desde este punto empieza á levantarse sobre tres varas de la superficie de las aguas del Rio; y en las mayores avenidas la cubre el agua un Pie; pero como los arboles le quitan la velocidad, y no llega á 24 oras la creciente, no hace daño en sus avitaciones, ni en los sembrados que alli tienen.

Una y otra orilla del Rio grande están pobladas de arboles muy unidos: su clase son Seybas, Amates, Sauzes, Guaromos, é Higuerillos, toda madera inutil por su poca solidez. Desde el rancho de los Ingleses adelante se observan en las orillas algunos arboles de Cacao, muchos de Platanos, y mucha Sarza. El terreno se va elevando suavemente hasta la falda de los Montes. Se hallan algunas Sabanas espaciosas, y todo de excelente calidad, y á proposito para siembras de Cacao, Cafe, Algodon, Cañadulce, Añil, Mais y toda especie de semillas.

El Rio nuevo nombrado asi por los vecinos del Pueblo Gualan (que todos los años bajan á hacer alli sus pesquerias) y por los del Valle Quimistan conocido por Cuiamel del Valle, es abundante de Pezes Bobos y Roncadores. A 2 leguas de la boca de este rio empiezan los saltos y las corrientes muy vivas. Desde este rio al de las Animas hay 12 leguas y 22 de la boca de Motagua: en este intermedio se halla el de Chichagualilla, que no produce pezes de utilidad. El de los Platanos, nombrado asi por la abundancia de este fruto, que tiene en sus inmediaciones, abunda en Bobos y Roncadores: El de Cuchar; y también se hallan los tres barrancos, la quebrada del Biscoyol, y del Mono, y los arroyos de la Cuchara, y del Cañal. Las producciones que se observan en las orillas del Rio grande, calidad de tierras desde ellas hasta las faldas de los montes, son las mismas, que se ha dicho tiene desde los ranchos de los Negros Ingleses hasta Rio nuevo. En esta porcion del rio hay muchos islotes, ó callos; tornos ó bueltos como en la anterior: 11 bajos de 5 á 6 palmos de agua: su fondo, islotes, y playas de Arena fina: el Rio en general conserva de 8 hasta 24 palmos de agua, y su corriente o velocidad es de media Milla por ora.

Desde el rio de las Animas al de Lagartos hay 10 leguas y 32 de la boca de Motagua. En este intermedio se hallan 
los rios de Francisco, el de Bobos, el Juyama, Riachuelo, y el de Tepemechin, todos producen Bobos y Roncadores. Tambien se halla el Arroyo de Bobos, quebrada del Descanso, y el barranco de la Vijia. Las corrientes de este pedazo del Rio, son de una y media Milla por ora: el suelo, playas, e islotes o callos, de cascajo menudo: la profundidad de agua es en todo él, desde 5 á 10 palmos. Toda esta porcion de rio está llena de palos, troncos ó Empalizadas, que en gran parte hace dificil, y peligrosa la navegacion. Las producciones de sus orillas en punto á maderas, plantas de Cacao, y Zarza, son iguales á las que se han dicho anteriormente; como tambien en punto á las tierras de sus inmediaciones ofrecen las mismas producciones que aquellas.

Desde el Rio Lagartos hasta el encuentro hay 7 leguas, y 39 de la boca de Motagua: en este intermedio se hallan el Rio Morja, y Jubuco, ambos abundantisimos de Pezes, y maderas, de Cedro y Cobanos, para construir qualquiera obra, y de todas magnitudes: de manera que hay Cedros que tienen tres varas de diametro, y en proporcion para conducirlos por dicho Rio hasta introducirlos en Motagua. A la distancia de una legua de la boca de ambos rios se hallan las Sabanas de Capaculpo, de 4 leguas en cuadro, y la Vega de Santa Catalina que tiene 5 leguas de largo, y 4 de ancho, cuyas tierras son de excelente calidad para producir toda especie de frutos, y cria de Ganados Bacuno y Mular. Tambien se halla la Quebrada de Santa Catalina en donde empiezan los Ranchos y Haciendas de los vecinos del Pueblo de Gualan, que con Canoas bajan por el Rio á hacer sus siembras, en donde se mantienen mucha parte del año: hasta recoger la cosecha. Se encuentra igualmente el rio Quirigua, y Managua: á las inmediaciones de este, está el Real de Utrera donde se construyó la Galera Santa Rosalía, que bajó por Motagua. El encuentro, Canoage [se trata de realizar cabotaje en una canoa], ó vado, es el paso preciso de los Arrieros que conducen á esta Capital los efectos que vienen de Europa, por via de Honduras, y los que de este Reyno llevan á España.

El suelo, Playas, y Callos, o Islotes, de esta porcion de Rio, son de cascajo menudo, la corriente en general de una y media Milla por ora: la profundidad de aguas es de 4 á 10 palmos. Tiene seis corrientes las 3 de dos y media milla por ora, y las otros 3 de 3 millas, de 3 á 4 palmos de agua. Tambien hay algunos Islotes; o Callos, Tornos y retornos como en la anterior. Las tierras de ambas orillas tienen las mismas proporciones, y producciones, que se ha dicho anteriormente.

Desde el encuentro al Pueblo de Gualan hay 7 leguas y 46 de la boca de Motagua. En este intermedio se hallan los rios de la Palmilla, el de Tipon, el Mestizo, el de Lobos, el de Biafara, el de la Puerta, el de los Limones, y el de Gualen: todos de poca consideracion en tiempo de seca; pero en Invierno traen mucha agua. Tambien hay las quebradas de los Ansanitos, y del Chaguite. Este trozo de rio tiene de ancho de 40 á 80 varas: su suelo, playas, callos o islotes son Cascajo de mediana magnitud. Tiene 14 corrientes: 4 de 2 millas por ora de velocidad: 4 de dos millas y media por ora: 4 de 3 millas: y 2 de 3 y media millas, con la profundidad todas de 3 á 6 palmos de agua: en lo restante del rio de 7 hasta veinte palmos; y en lo general la corriente ó velocidad es de una y media Milla por ora. Una y otra orilla del río grande, están llenas de Ranchos o Haciendas de los vecinos de Gualan, en las que cosechan abundancia de Mais, Frijol y algun Cacao: la tierra es aparente para este fruto, y demas que produce la America. El Pueblo de Gualan tiene de vecindario 200 familias, que llaman Ladinos, poco mas ó menos, y 250 Indios tributarios: es abundante en Mais, Frijol, y mediana cosecha de Cacao: en sus inmediaciones hay algunas vegas, y cariadas de excelente tierra, que con facilidad se le puede dar riego de los ríos inmediatos, y por este medio se aumentarian considerablemente varias cosechas, en particular la de Cacao.

Hasta este punto me servi de las embarcaciones que saque de Omoa. De aqui adelante usé de las Canoas por haverme informado que las corrientes del rio grande eran mucho mayores, y tenia algunos chiflones de considerable velocidad, y peligro; por cuya razon se volvieron por el rio á aquel Puerto la Piragua, y Bote con toda la tripulacion que saqué de allí, y para continuar el reconocimiento de dicho rio, tomé Indios prácticos del Pueblo de Gualan, que me acompañaron hasta la union del rio Chicosapote con Motagua.

Desde el Pueblo de Gualan, al de San Pablo hay 7 leguas y 53 de la boca de Motagua: En esta distancia se hallan los rios nombrados, Amayuelas, Achotes, Santiago, 
San Pedro y Cumusna: traen en Verano poco agua, y en Invierno son caudalosos. A legua y media de la boca de los cuatro primeros, acia la Sierra, hay abundancia de maderas de Cedro de todos tamaños, de buena calidad, y en proporcion de conducirlas por estos rios a Motagua, en tiempo de Invierno que crecen las aguas. Este pedazo de rio grande tiene de ancho de 40 á 60 varas: su fondo en lo general es de 12 á 30 palmos de agua, y su velocidad de una y media milla por ora: va encajonado entre algunos escapados de piedra: hay 12 corrientes ó chiflones: 5 de dos y media millas de velocidad por ora, y de 8 á 10 palmos de agua; 5 de 3 millas de velocidad, y de 7 á 8 palmos de agua: y dos de 5 millas de velocidad, y de 6 á 7 palmos de agua, todos peligrosos por los peñascos, y piedras sueltas de que el fondo de este trozo de rio, y sus orillas, callos é islotes estan llenos. Las tierras de sus inmediaciones son montuosas, y quebradas, secas y esteriles: producen poca arboleda, y solo en las vegas, cañadas, y en las orillas de los ríos subalternos, hay alguna fertilidad. Las Haciendas que se hallan en todo este distrito son de Ganado bacuno, y muy escasas las cosechas de Mais y Frijol, que son los unicos frutos que cojen; pero pueden aumentarse por medio del riego que se les puede dar con facilidad, tomando las aguas de estos rios á la altura correspondiente, ó parajes mas proporcionados. El vecindario de este Pueblo se compone de 110 Indios tributarios.

Desde el Pueblo de S. Pablo al de Chimalapa hay 11 leguas y 64 de la boca de Motagua: en esta distancia se hallan los rios Zacapa (caudaloso en Invierno, y aun en Verano muy regular), Rio hondo, Lomexia, Tuculutan, de la Palmilla, y el del Guijo: todos de poco agua en Verano, y caudalosos en Invierno. Esta porcion del Rio grande, tiene de ancho de 40 á 60 varas: va encajonado entre escarpados de piedra: el fondo, playas y orillas están llenas de peñascos y piedra suelta de alguna magnitud: la corriente ó belocidad de las aguas, en lo general, es de 1 y media milla por ora, y la profundidad de 8 á 12 palmos. Tiene 8 corrientes o chiflones: 2 con la velocidad de tres millas por ora, con el fondo de 6 á 7 palmos de agua; $y$ 6 de 2 y media millas por ora, fondo de 5 á 6 palmos de agua; todos de bastante peligro. En las inmediaciones de esta porcion de Rio grande se halla el Valle de la
Lampara, que consta de 15 familias de Ladinos; y 4 de Indios tributarios: el Vale de S. José de 18 á 20 familias de Ladinos: el del Jiote de 19 familias: y el de Antón Bran de 5 familias todos Ladinos. Estas Haciendas son de Ganado bacuno y lanar, y algún poco del mular: todo el terreno es montuoso y quebrado, de poca arboleda, seco y esteril; por cuyo motibo solo cosechan en Invierno, Mais. El Pueblo de Chimalapa se compone de 20 familias de ladinos y 110 de Indios tributarios.

De este Pueblo al de Casaguastlan hay 3 leguas y 67 de la boca de Motagua. En esta distancia se hallan los rios de Chimalapa, de bastante agua en Verano, y en Invierno caudaloso; y el de Uuis, seco en Verano y caudaloso en Invierno. La porcion del Rio grande tiene de ancho de 40 á 50 varas: su suelo, playas, islotes o callos, y orillas están Ilenos de peñasco y piedra suelta: la profundidad de agua en todo el es de 12 a 24 palmos, y su velocidad de 2 millas por ora. En las orillas hay algunas vegas en que los vecinos de dicho Pueblo tienen sus milpas, cojen Mais, Frijol, Caña dulce, y Cacao. Se compone el vecindario de 170 Indios tributarios: las tierras inmediatas son de la misma calidad y circunstancias que se ha dicho anteriormente.

Del Pueblo de Casaguastlan al de la Magdalena hay 5 leguas y 72 de la boca de Motagua; en cuya distancia se halla el rio de las Obejas, seco en Verano y caudaloso en Invierno: las orillas, fondo, playas, e islotes del Rio grande están llenas de peñascos y piedras sueltas, y va encajonado entre escarpados de piedra: su ancho es de 40 á 50 varas, la profundidad del agua, en lo general, es de 12 á 16 palmos, y la velocidad de 2 millas por ora. Las tierras inmediatas son montuosas, secas y esteriles; de muy poca arboleda, y pastos para el Ganado; solo en las cañadas, y orillas del Rio, hay algunas porciones de tierra de buena calidad para sementeras, en las cuales los Indios del Pueblo de la Magdalena (cuyo vecindario consta de 800 tributarios) tienen sus milpas de Mais, Caña dulce y Cacao de que cojen una mediana cosecha.

Desde la Magdalena a la union del rio Chicosapote con Motagua, hay 8 leguas y 80 de la boca de Motagua; á una legua de la Magdalena está el Pueblo de S. Agustin: consta su vecindario de 2200 Indios tributarios; los quales en las orillas del rio de este nombre y en las del Rio grande tienen sus milpas, y cojen con abundancia Mais, Caña 
dulce y Cacao: en esta distancia se hallan los ríos de San Agustín, Tulumaxa, Tocoy, Guastatoya y Chicosapote. Se halla tambien la Hacienda de San Marcos, de Ganado bacuno y mular. Tiene este trozo del Rio grande, 13 corrientes o chiflones: 4 de 5 millas de velocidad por ora, 2 de 4 millas, 5 de 3 millas y 2 de 2 y media millas con el fondo de agua de 2, 3 y 4 palmos: lo restante dél, en lo general, es de 5 a 10 palmos; y la velocidad de 2 millas por ora. El ancho del rio es de 30 á 40 varas: va encajonado entre escarpados de piedra: el suelo, orillas, playas, y callos están llenos de peñascos y piedras sueltas; por cuyo motibo es muy peligrosa la navegacion en esta parte. Las tierras inmediatas, son secas y esteriles: de poca Arboleda, y pastos para el Ganado: son montuosas y quebradas; por cuya causa no son aproposito para la Agricultura. $Y$ haviendo hallado solo un palmo y medio de agua a la entrada del cañon de Chicosapote, y no ser suficiente para proseguir la navegacion con las canoas, para continuar el reconocimiento del citado rio Motagua, lo suspendi en este punto.

El dia 4 de Mayo de este año, se dio principio al reconocimiento de este rio, subiendo con las embarcaciones que se ha dicho, llegando el dia 15 de Junio a la union del rio Chicosapote con Motagua, en donde se dio fin, por no tener suficientes aguas para continuar la Navegacion: en todo este tiempo conservó el rio la cantidad de agua que se expresa en la relacion antecedente.

Por las noticias que se tomaron de los vecinos de Gualan, y demas que avitan á las orillas del Rio grande, se sabe, que en los meses de Mayo, Junio, Julio, Octubre, Noviembre, Diciembre y Enero, las aguas en dicho rio se conservan en una buena proporcion, con algunos intermedios de mayor cantidad por razon de las crecidas que suele haver. En Agosto y Septiembre son las mayores crecientes, y traen cantidad de maderos, troncos o palos; en cuyo tiempo es mas dificil y peligrosa la navegacion: En Febrero, Marzo y Abril son las menores aguas.

Las dificultades que se presentan en dicho rio para que en todos tiempos sea navegable, son los bajos, los troncos, palos o empalizadas, y las corrientes ó chiflones, que se expresan en la relacion que antecede; pero estos obstaculos son vencibles: los chiflones ó corrientes los causan, que el suelo del rio en aquella porcion, está mas elevado que la parte inferior donde remata, y teniendo mayor inclinacion, las aguas, tienen mas velocidad; pero en todos ellos se observa que poco antes del principio, $y$ al extremo donde concluyen hay una poza, y esto facilita poderlas suavizar, rebaxando el fondo lo necesario, de manera que depositando las arenas ó cascajos en dichas pozas, tomarán las aguas menor velocidad, y se aumentara la profundidad en aquellas partes, facilitando el paso á las embarcaciones que se usarán en el rio. Las empalizadas estorban, hacen dificil, y aun peligrosa la navegacion, en la parte que de el ocupan, cuyo inconveniente solo puede evitarse limpiandolas enteramente; pues aunque algunas que están en las orillas no embarazan quando las aguas las tienen descubiertas, ocultandose en las crecientes, pueden causar daño, y tal vez la perdida de alguna embarcacion que tropezase en uno de tantos troncos.

Los tornos ó bueltas que forma el rio, lejos de perjudicar son convenientes á la subida de los buques. Seria facil acortar la distancia abriendo una zanja de unos á otros que formarse nueva madre á las aguas; pero tomarían inevitablemente mayor velocidad, resultando chiflones dificiles de vencerse. No son menos favorables los callos ó islotes, porque dividiendo el rio en dos canales, con mayor cantidad de agua el uno que el otro, podrá usarse del menor en las crecientes, y del mayor en tiempo de seca: Ademas de esto servirán de abrigo y anclage á las embarcaciones de noche, y en una fuerte avenida; cuyo resguardo proporcionan tambien los tornos ó bueltos.

La dificultad mayor de este rio consiste en su barra, de la que me parece no se debe hacer uso; pues aunque su canalizo es proporcionado para embarcaciones que calen de 5 á 6 palmos de agua, y en algun tiempo del año para mayor porte, se expondrian á perderse los intereses, y aun las vidas de las tripulaciones, como puede inferirse de lo que en esta relacion queda referido de las circunstancias de la costa, y la experiencia que hay de algunas desgracias.

Mediante este arriesgado obstaculo, es preciso ocurrir á otros medios mas faciles y seguros, al fin de no privar al Estado, y al Comercio de las grandes utilidades que resultarán poniendo en corriente la navegacion de este rio. Conseguiranse estas abriendo un camino por la playa 
desde Omoa, á Motagua, que por las bueltas ó tornos que formará, será de 8 á 10 leguas. En esta distancia se hallan los 5 rios que demuestra el plano. Los 4 primeros son de poca consideracion, y en ningun tiempo niegan el paso, si se exeptuan las grandes crecientes que nunca llegan á 24 horas. El otro nombrado el rio Tinto, solo en verano se puede vadearse; pero quedará facilitado su transito en Invierno con una canoa, o barco chato, como se usa para el paso de otros rios.

Las embarcaciones adecuadas al uso del Motagua deben ser de construccion plana, ó piraguas que calen de 4 a 5 palmos de Agua, para que en ningun tiempo se interrumpa la navegacion, capaces de admitir 100 zurrones de Añil, ó 1000 arrobas de otros efectos: han de tener cubierta para evitar las averias de las llubias, y otros accidentes. Una toldilla para resguardo de viveres, y descanso de la gente. Un Molinete para facilitar el uso de la espia. Dos resones, y un Cayuquito para tenderlos alternatibamente: con cuyos auxilios se adelantará la navegacion, con menos fatiga de los marineros. Cada una de estas embarcaciones estará provista de un Prisme de madera con muchas puntas de fierro, en forma de un erizo, para que pendiente de la popa con dos cadenas, arrastrando por el fondo de rio, remueba las arenas y cascajo, que la velocidad de las aguas conducirá de los parages mas elebados, á los mas hondos: asi se concerbará limpio el canalizo, y con la cantidad de agua necessaria en todos tiempos. Esta clase de barcos podrán manejarse con seis hombres y un patron.

Luego que la navegacion del rio esté corriente hasta Gualan: construidos los barcos y almacenes en los parages destinados, y abierto el camino de Omoa, que queda propuesto, se podrá disponer que los registros de España tengas su paradero en este puerto, executando en el su descarga. Los efectos serán conducidos por los arrieros de Omoa, a un deposito, inmediato al embarcadero de Motagua; y en él lo recibirán los barcos del rio para conducirlos á Gualan; desde donde se transportarán por otros arrieros á esta capital. Los retornos, ó cargazones de regreso, se governarán del mismo modo.

Estas maniobras no aumentan los embarazos practicos del Golfo; en cuya boca es preciso depositar los cargamentos conducidos por las embarcaciones menores desde los buques principales, que están al ancla á distancia de legua y media. De este deposito, conocido comunmente por Bodegas bajas, los toman los barcos de alijo, que trajinan el rio, para transportarlos a las Bodegas altas, y de estas los arrieros para la capital: de modo que han de pasar por la misma variedad de manos que se propone en este proyecto.

Las utilidades y ventajas que resultarán al Estado, al Comercio, y al Público abriendo la navegación de este rio, son tan conocidas que quasi es ocioso tratar de ellas. A primera vista se agolpan el ahorro del barco de alijo que necesita traer todo Registro de España. la gente que ha de tripularlo con consideracion al excesibo trabajo, y al mortal clima del Golfo hasta Bodegas altas; pues aunque el temperamento de Omoa no sea mejor, faltandole al marinero aquel excesibo trabajo por una parte, y teniendo en sus enfermedades los auxilios de que carece el Golfo, por otra, serán muy menos los funestos efectos. Los buques no tendrán las grandes demoras, inevitables hasta ahora, $\mathrm{ni}$ quedarán sujetos á regresar en las mas borrascosas estancias, asi para estos mares, como para los de Europa; cuyas circunstancias pueden hacer una sensible baja en los fletes, y seguros maritimos. La pension, ó arrendamiento, que se paga por el terrazgo que ocupan las Bodegas altas al Convento de Santo Domingo: Las reparaciones que incesantemente necesitan asi estos almacenes, como el que está en la entrada del Golfo: Las estorciones, y robos que unos y otros padecen estos comerciantes: las demoras y fraudes de la arrieria que suele recibir doble carga tardando en entregarla mas de doble tiempo; y por ultimo, el excesivo porte de tierra que en lo principal dobla la partida al de mar, son articulos que deben producir cuantiosos ahorros, y mejoras. Apenas se saca de este Reyno otra produccion que el Añil, ni se introduce en el mas que aquellos efectos que pueden sufrir los riesgos, y costos tan excesibos que hoy se expenden; y por el Motagua entrarán á la circulacion variedad de renglones que den considerables aumentos al comercio, y alivios a estos pueblos. Las orillas de este rio son de buena calidad de tierras para toda especie de sementeras; particularmente desde Rio nuevo hasta 
Quiriguá, se llenarán de haciendas, estableciendose muchas familias que fomentarán las cosechas de Cacao, Algodon, Arros, Cafe, cañas de Azucar, Añil, Maiz, y otros frutos, que con la Zarza, y mas que sin cultivo alguno producen los bosques, se esportarán á muy poco costo. Podrán fundarse poblaciones á las orillas de los rios que se unen con Motagua, como que sus tierras ofrecen iguales proporciones. El temperamento de este rio es sano, como lo muestra la esperiencia. Los vecinos del pueblo de Gualan bajan todos los años hasta Rio nuevo á hacer sus pesquerias, en que gastan dos meses; y sin embargo de que todo este tiempo están metidos en el agua, no experimentan enfermedades; lo qual obserbé yo tambien en este reconocimiento, que en numero de 29 , bastante incomodadas de las lluvias y falta de abrigo por la noche, ninguno se enfermó.

Para la seguridad del Reyno, y evitar qualquiera invasion que los enemigos intenten por este rio, se deverá construir una pequeña fortificacion en el paraje nombrado el barranco de la Vijia, puesto aproposito para la defensa; porque estando en la mediania, de la boca del Motagua, al Pueblo de Gualan, podrá ser socorrida con facilidad, y prontitud, quando lo necesite. En tiempo de guerra se mantendrá una vigia en la boca, que observe qualquiera novedad que ocurre en la mar, y se recibirán los avisos con mucha brevedad para tomar las providencias que el caso pida. En todo el curso del rio hay muchos parages ventajosos para apostaderos de donde se puede rechazar y frustrar la idea á los que intenten subir por él; cuyos puestos pueden demarcase cuando se emprenda la limpia de las empalizadas; porque estando ahora muy cerrados de monte, no pueden determinarse Ios que ofrecen mayores ventajas, y por la misma razon tampoco puede resolverse la figura, y magnitud del fuerte que debe construirse en el barranco de la Vijia, hasta tener todo el terreno desmontado, y limpio: asi se evitará un herror que causaria muchos gastos, y perjuicios no eligiendo la situacion mas faborable, a una obra de esta naturaleza.

Las embarcaciones con las tripulaciones propuestas tardarán en subir desde la boca el río hasta Gualan 8 días; y en la bajada gastarán de 3 á 4: harán en un mes dos viajes. Supongamos que no hagan mas de uno, y que á la gente se pague á razón de 20 pesos al mes; importará el gasto de los 7 hombres 140 pesos. Las 1000 arrobas ó 100 zurrones, que podrá cargar cada uno de estos barcos, á real por arroba, importan 125 pesos y añadiendo igual cantidad por la carga de regreso, producirá el viage redondo 250 pesos; de que rebajado el gasto referido, quedarán á favor del buque o de su dueño 110 pesos cada mes. Si se construyesen las embarcaciones capaces de 2000 arrobas, ó 200 zurrones, con aumentar dos hombres a cada una será suficiente, y en este caso, por el calculo precedente, será la ganancia de 320 pesos. Estos portes se minorarán a proporcion de la facilidad de la navegacion, y perfeccion de los barcos para que puedan hacer mas viajes de los que aqui se subonen.

No se pueden por ahora calcular los gastos de conduccion de tierra desde Omoa al rio, ignorandose las proporciones, ó improporciones de este camino, abundancia, ó escases de pastos, y si podra ó no hacerse uso de carros; cuyas circunstancias pueden dar mucha bariacion al flete. Para hablar con propiedad en este articulo, es preciso quede sujeto a un reconocimiento del terreno, y direccion del camino.

Respeto que la porcion del Rio grande desde Gualan hasta donde se le une el rio Chicosapote, presenta mayores dificultades que vencer, consumo de tiempo, y de caudales, que la otra porcion intermedia de la boca á Gualan, he tenido por conveniente tratar de solo esta por ahora, para que vencidos los embarazos y establecida su navegacion, se empiecen desde luego á disfrutar, y hacer experiencia de las grandes felicidades que atraerá al Reyno, y su comercio, este proyecto; lo cual servirá de estimulo a fomentar con gusto lo restante de la empresa.

\section{NOTA}

La Ensenada de Santo Tomas está resguardada de todos los vientos: en la entrada tiene 5 brazas de agua: y 6 en lo interior hasta las mismas orillas, como en el plano se manifiesta. La distancia, por tierra, de esta Ensenada hasta el rio motagua, será de tres leguas poco mas ó menos: Si el terreno proporcionase la avertura de un canal de comunicacion, para que las embarcaciones 
que han de transitar este rio, llegasen al costado de los Registros de España, surtos en la misma Ensenada, a alijarlos, y cargarlos, seria mucho mas ventajoso este proyecto que el del camino de Omoa; porque quedaban vencidos los embarazos de poner en tierra las cargazones y su conduccion hasta el rio (con la variacion de manos que se ha indicado), pasando directamente á Gualan por agua. Si la obra del canal, por algunos invencibles obstaculos, fuese impracticable, queda el recurso de abrir un camino desde Santo Tomas hasta el rio, por donde se conduzca la carga en carros, ó alomo de bestias a un deposito o almacen como el que se ha dicho de la boca de Motagua.

Verificada la avertura del canal, o bien sea el camino ultimamente propuesto, las mejores para la Real Hacienda, y para el Comercio, serán de mucha consideracion; porque deviendose fortificar este puesto de un modo capaz de rechazar toda inbasion de enemigos, dejando cerrada la entrada en el Reyno, y asegurados los interezes del publico, se excusaria la construccion del fuerte que se ha dicho deve haver en el rio para el mismo fin, y aun los gastos que ocasiona el Castillo de Omoa, como se dirá abajo.

En la relacion que pasé á V.E., con fecha de 30 de Abril de este año, se manifiesta el estado del Castillo San Fernando de Omoa. Los reparos indispensables que necesita para su conserbacion, y las obras que se deven añadir para ponerlo en estado de defensa, impenderán los costos que se calcularon; pero todo esto no escusa que dicho Castillo quede dominado de la Loma, solo distante 800 varas.

Si se adaptase fortificar la Ensenada de Santo Tomas, convendria abandonar el Castillo de Omoa, pasando la guarnicion, Cajas Reales, Empleados, esclavos del Rey, y todo el vecindario al nuevo destino de Santo Tomas: Ahorraria la Real Hacienda los gastos de reparacion de dicho Castillo, los de construccion de fuerte en el rio de Motagua, los del Castillo de San Felipe del Golfo, que en este caso debe abandonarse, y quedaria la costa mas defendida. Para que los enemigos no se introdugesen por los parages que se abandonasen, convendria inutilizar el camino de Omoa á San Pedro Sula, el de Bodegas altas al encuentro ó vado del rio Motagua, y embarazar la porcion de este intermedia desde su boca a la union del canal, o camino que venga de Santo Tomas; cuya Ensenada seria la precisa entrada para el Reyno.

En mi citada relacion de 30 de Agosto de este año se notará que los rios Chamalecon y Ulua, inmediatos á Omoa, son navegables con embarcaciones Chatas, ó Piraguas; pero que el Castillo de Omoa no puede impedirlo, y que la defensa debe ser en los apostaderos que en ella se expresan.

Los rios de navegacion son tan importantes al aumento de la poblacion, y de la agricultura, que todo lo que disminuyen de hombres, y acemilas en los acarretos terrestres, es otro tanto poder que se introduce en los campos, y en los pueblos. El rio Motagua tiene, como se ha dicho, excelente disposicion para ambos fines, con ventajas de que carecen los que su situacion imposibilita la saca de sus producciones; sobre que no hay necesidad de citar ejemplos por ser materia tan de bulto. Este conocimiento me ha movido á proponer á V.E. la avertura del camino ó canal mencionados, con el cual adquirirá este proyecto el mayor grado de perfeccion.

Pero para proceder a su execucion con los solidos conocimientos que necesita un objeto de tanta magnitud, que abrasa la traslacion de la guarnicion, y vecindario de Omoa á la ensenada de Santo Tomas; construccion de fortaleza en este destino, y abandono del Castillo existente en aquel; es indispensable que se proceda a un prolijo reconocimiento de dicha Ensenada, y terrenos inmediatos hasta el rio Motagua, para hacer una combinacion de todas sus circunstancias, y deducir las mayores ventajas que ofrezca este paraje sobre los demas reconocidos.

Dejo expuesto á V.E. todos los medios, que á mis cortas luces han ocurrido, para la introduccion y extraccion de efectos en este Reyno por el rio de Motagua, y si V.E. fuese servido de adaptarlos abré logrado la mayor satisfaccion.

Nuestro Señor guarde a V.E. muchos años. Nueva Guatemala y Noviembre 2 de 1792.

\section{Exmo. Señor \\ Antonio Porta y Costa}

\author{
A Exmo. Señor Presidente \\ D. Bernardo Troncoso
}




\section{Notas}

${ }^{1}$ Archivo General de la Nación, México D.F., Instituciones coloniales, ramo Impresos Oficiales, vol. 52, fojas 213223.

${ }^{2}$ Se conservan en el texto las expresiones, ortografía, puntuación y estilo originales del documento.

${ }^{3}$ Cieno blando, suelto y pegajoso, de color oscuro, que se halla en algunos lugares del fondo del mar o de los ríos, y en el de los recipientes o lugares en donde hay o ha habido agua largo tiempo (RAE, Diccionario de la lengua española, s.v. "lama”. Disponible en: http:// www.rae.es/).
${ }^{4}$ Molusco lamelibranquio marino de aspecto vermiforme, con sifones desmesuradamente largos y concha muy pequeña, que deja descubierta la mayor parte del cuerpo. Las valvas de la concha, funcionando como mandíbulas, perforan las maderas sumergidas, practican en ellas galerías que el propio animal reviste de una materia calcárea segregada por el manto, y causan así graves daños en las construcciones navales (RAE, Diccionario de la lengua española, s.v. "broma". Disponible en: http://www.rae.es/).

${ }^{5}$ Desafortunadamente, en el expediente no se ha encontrado el plano preparado por el ingeniero Antonio Porta.

${ }^{6}$ Se trata de la recolecta de zarzamora. 


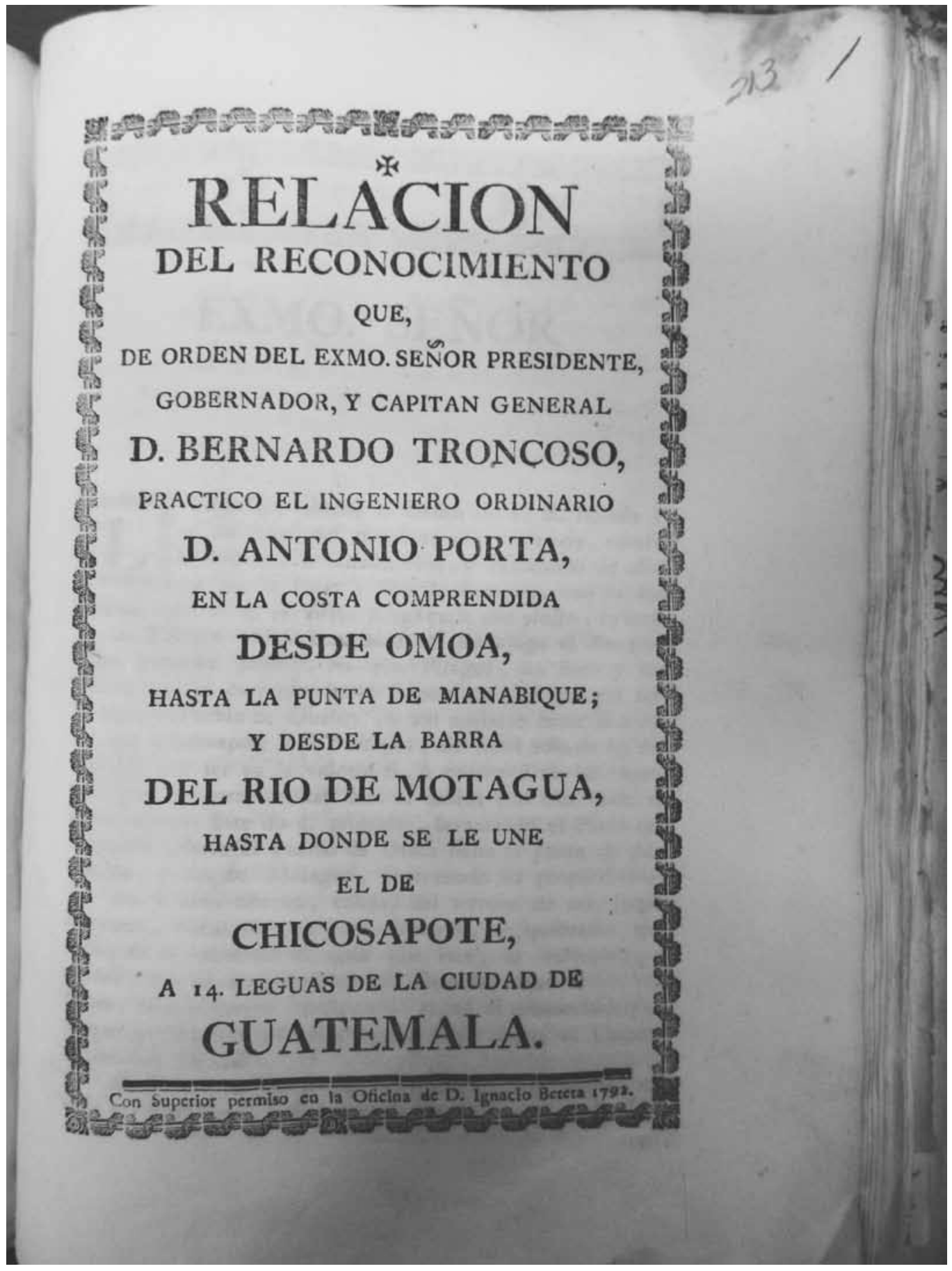

Fuente: Archivo General de la Nación, México, D. F., Intituciones coloniales, ramo Impresos oficiales, vol. 52, foja 213. 


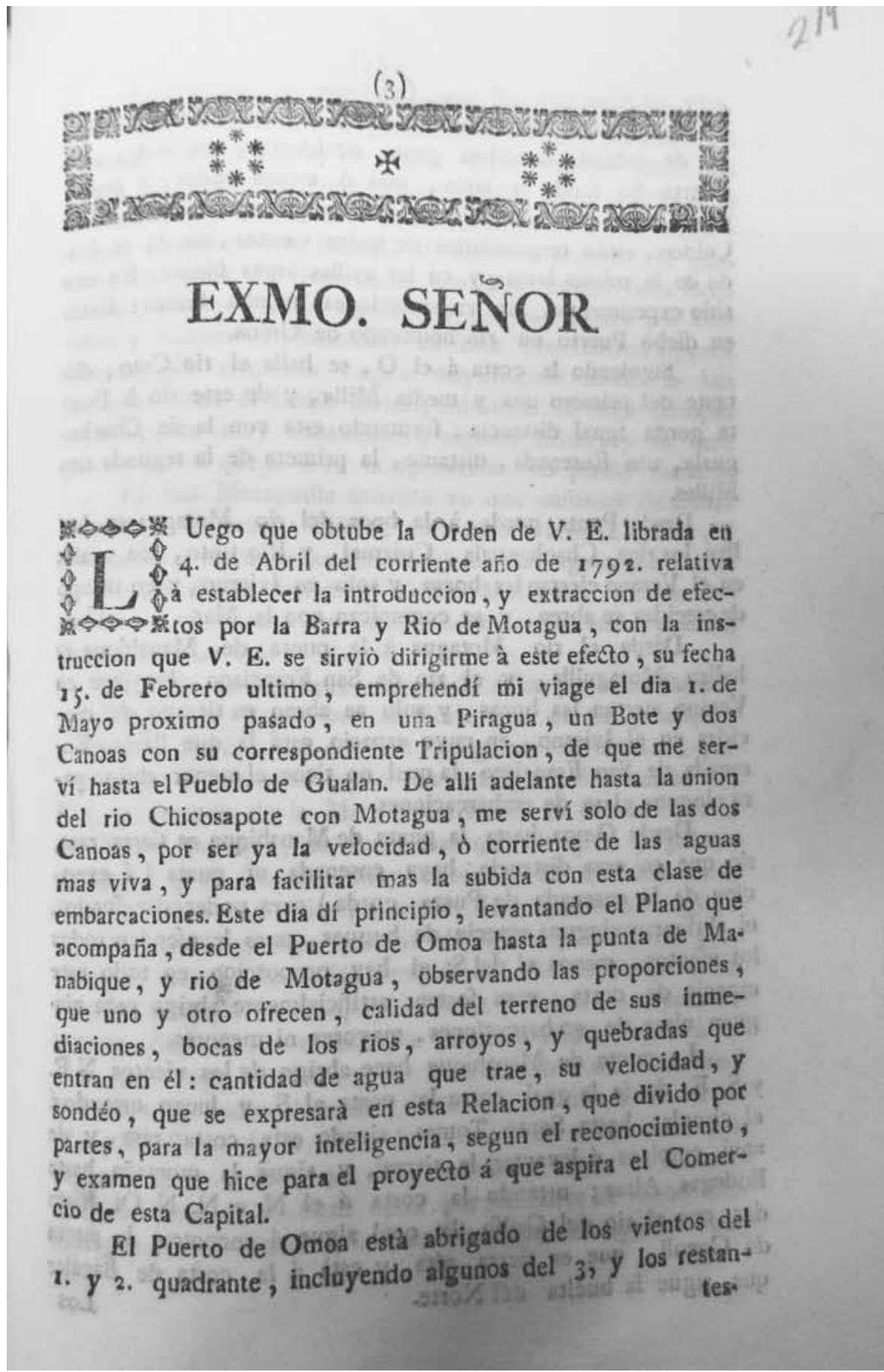

Fuente: Archivo General de la Nación, México, D. F., Intituciones coloniales, ramo Impresos oficiales, vol. 52, foja 214. 


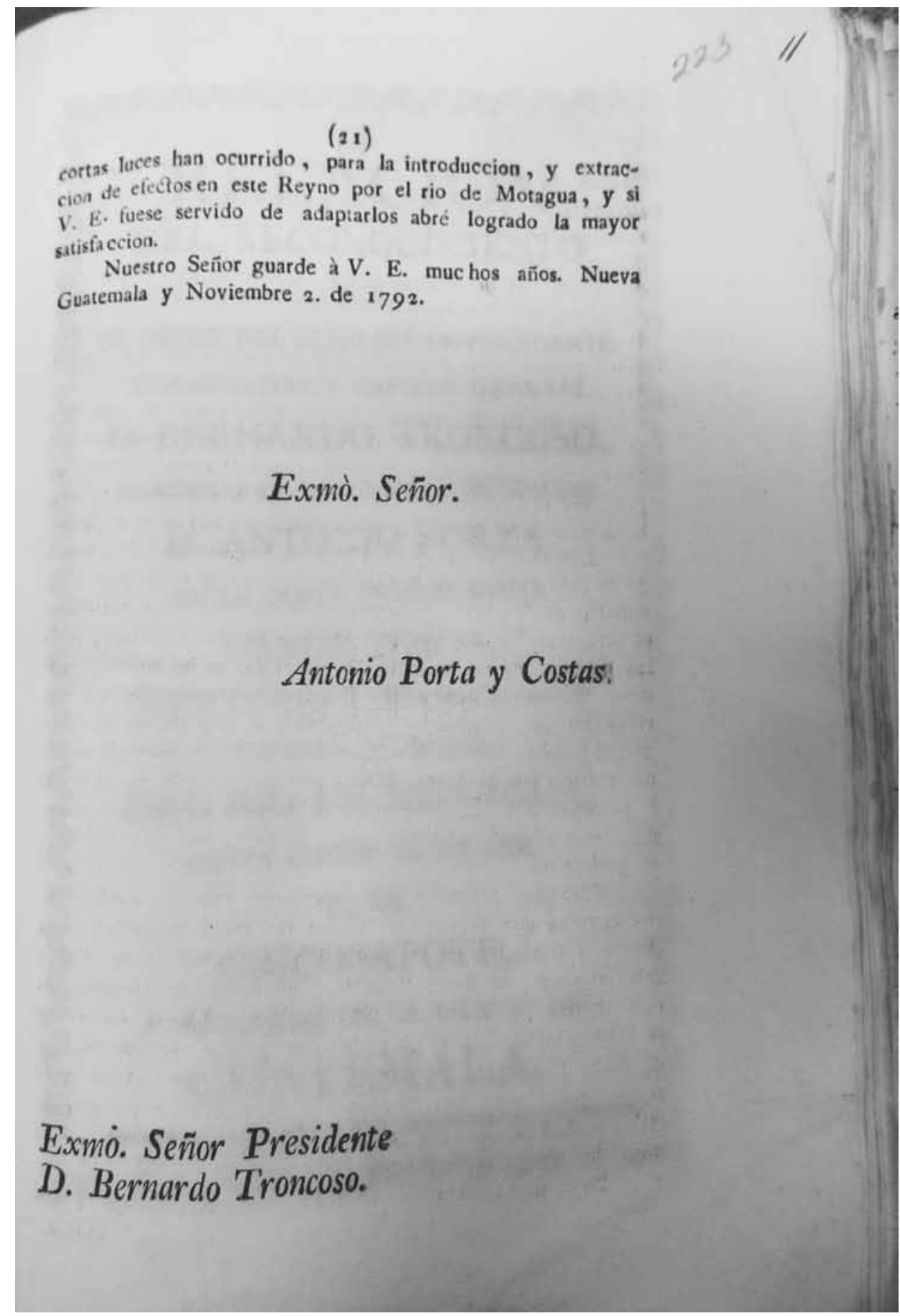

Fuente: Archivo General de la Nación, México, D. F., Intituciones coloniales, ramo Impresos oficiales, vol. 52, foja 223. 